\title{
ELITES EM PERSPECTIVA: UMA DISCUSSÃO SOBRE HIERARQUIAS, COMPOSIÇÃO DA RIQUEZA E CONSOLIDAÇÃO DOS GRUPOS HEGEMÔNICOS EM SÃO JOÃO DEL REI
}

\author{
ELITES IN PERSPECTIVE: A DISCUSSION ABOUT HIERARCHIES, \\ COMPOSITION OF WEALTH AND CONSOLIDATION OF HEGEMONIC \\ GROUPS IN SÃO JOÃO DEL REI
}

\author{
Keila Cecília de Melo ${ }^{1}$ \\ Mestranda em História pela UFSJ \\ E-mail: keilacmelo@ig.com.br
}

RESUMO: O artigo analisa aspectos econômicos da elite colonial mineira a partir de meados do século XVIII, mediante a investigação empírica da sociedade de São João Del Rei. O comércio em São João assumiu um papel central na liquidez da economia regional, permitindo a formação de grupos hegemônicos no século XIX. Mas há ainda muitas dúvidas sobre quem era essa elite no século XVIII. Com base em pesquisa prosopográfica que reconstrói os caminhos dos homens arrolados por Domingos Nunes Vieira como os mais ricos da capitania de Minas Gerais no ano de 1756, percebemos que a elite mineira que se formou no século XVIII diferia dos padrões mais gerais para a caracterização de grupos hegemônicos em outras regiões do Brasil, no mesmo período.

PALAVRAS CHAVES: Elites Econômicas. Sociedade Colonial. Hierarquia.

\begin{abstract}
This paper analyses the economic aspects of the colonial elite of Minas Gerais the eighteenth century by investigation of the São João Del Rei society. Trade in São João Del Rei assumed a central role in the liquidity of the regional economy, allowing the formation of hegemonic groups in the nineteenth century. But there are still many doubts about who was this elite in the eighteenth century. Based on prosopographical research that reconstructs the paths of the men regarded by Domingos Nunes Vieira as the richest of the Minas Gerais in the year of 1756 , we concluded that the mineira elite formed in the eighteenth century differed from the more general models for characterization of hegemonic groups in other regions of Brazil.
\end{abstract}

KEYWORDS: Economic Elites. Colonial Society. Hierarchy. 


\section{Considerações preliminares}

As análises aqui exploradas visam responder a algumas questões sobre a gênese da elite colonial mineira, ancoradas nos resultados alcançados para a vila de São João Del Rei. A proposta do artigo é investigar como era composta a elite mineira e quais as suas peculiaridades por meio da análise de um grupo de indivíduos oficialmente declarado como os mais abastados da capitania no ano de $1756^{2}$ e pela comparação com os homens mais ricos de São João Del Rei a partir de 1831 estudados por Graça Filho (2002).

$\mathrm{Na}$ intenção de aludir à amplitude analítica do conceito 'elite', realizamos uma breve discussão sobre suas origens, situando o tema no âmago da discussão historiográfica pertinente. A teoria das elites ou das minorias organizadas se refere a dois pólos existentes em toda sociedade - grupos proeminentes que detém o poder se beneficiando, por conseguinte, do mando e de privilégios e a parcela majoritária dos componentes da mesma, que é explorada ${ }^{3}$. A respeito dessa acepção, Hespanha (2005, p.44) afirma que o termo 'elites' torna-se abrangente demais deixando de ser operativo, haja vista que "considerando as coisas assim, todos, em algum sentido - em algum plano - são tendencialmente elites" porque em algum momento são reconhecidos como "detentores de uma legitimidade para dirigir".

Segundo a definição de Fernanda Bicalho (2005), o termo elites, tratando-se do Antigo Regime no Brasil, assumia uma conotação mais econômica. A autora afirma que, assim como as elites do Reino, as elites coloniais eram caracterizadas por amplo patrimônio, pela ocupação de cargos administrativos e recebimento de mercês régias por serviços prestados acrescentando-se a isso a posse de escravos, mais específica da realidade brasileira.

\footnotetext{
${ }^{1}$ Agência financiadora: CNPQ. Pesquisa orientada pelo prof. Dr. Afonso de Alencastro Graça Filho, professor titular da Universidade Federal de São João Del Rei, Minas Gerais.

${ }^{2}$ Lista feita por Domingos Nunes Vieira, intendente da Comarca de Sabará, que assim escreveu ao secretário de Estado em 24 de julho de 1756 informando os nomes dos homens mais abastados da capitania de Minas. Documento disponibilizado no Arquivo Ultramarino.

${ }^{3}$ Cf. BOBBIO, Norberto. Teoria das elites. In: BOBBIO, Norberto; MATTEUCCI, Nicola; PASQUINO, Gianfranco (Orgs). Dicionário de política. Brasília: EDUNB, 1992. O autor realiza uma discussão bastante didática a respeito da teoria das elites, suas raízes, principais expoentes, críticas e relações entre as concepções formuladas.
}

Oficina do Historiador, Porto Alegre, EDIPUCRS, v. 7, n. 1, jan./jun. 2014, p. 4-22. 
As sociedades de Antigo Regime eram perpassadas pelas 'lutas de representações' que vislumbravam a criação e manutenção das hierarquias sociais. Para Chartier, (2002, p.75) a representação neste tipo de sociedade significava a exposição pública em que o simbólico excedia a coisa significada, visava à 'teatralização da vida social' ou seja, uma representação subjetiva que refletia uma distorção da realidade. Nesse sentido, "transforma-se em máquina de fabricar respeito e submissão, em um instrumento que produz uma imposição interiorizada, necessária lá onde falta o possível recurso à força bruta". Consideramos que esse mecanismo era utilizado para caracterizar como elite os grupos sociais hierarquizados seja pelos coeficientes de riqueza ou pela inserção política e social.

Para efeito de análise, consideramos como elite os homens arrolados por Domingos Nunes Vieira como os mais abastados da capitania, ainda que suas fortunas, em alguns casos, não atingissem o valor médio de monte-mor equivalente a dez contos de réis, cálculo das fortunas para os homens abastados de Minas Gerais utilizado por Almeida (2005). O trabalho com essa listagem serve ao propósito de problematizar os critérios para classificar a elite econômica em formação em Minas; verificar a situação social, a composição da riqueza e influência social desses indivíduos arrolados; e, sobretudo, testar as generalizações de alguns autores erigidas unicamente sobre as descrições de autoridades metropolitanas.

$\mathrm{Na}$ busca de compreender a complexidade do tecido social, esse artigo visa promover o diálogo profícuo entre as teorias da história social econômica e as proposições metodológicas da Micro-História utilizando como quadro de experimentação historiográfica o recorte administrativo da Comarca do Rio das Mortes, com ênfase na Vila de São João del Rei, cabeça de comarca. O estudo de caso, por meio da metodologia da Micro-História, servirá ao propósito de lançar luz sobre as estratégias de enriquecimento empregadas em São João del Rei. A análise de casos "excepcionais" poderá revelar a complexidade das estratégias sociais e de poder (REVEL, 1998; LIMA, 2006; LEVI, 1992; LEVI, 2002; CHARLE, 2006). O que se ambiciona é experimentar suposições consideradas macro-históricas em uma escala de observação menor. Rojas afirma que os historiadores partem "siempre de hipótesis macro-históricas y de problemas macrohistóricos, y luego descienden a esse nível "micro" para usarlo sobre todo como espacio de experimentación historiográfica (GONZÁLES et al, 2005)"”. 
As fontes que possibilitaram a incursão pelo universo dessa elite em formação em meados do século XVIII foram - a lista dos homens mais abastados de Minas sob a guarda do AHU Arquivo Histórico Ultramarino, os acórdãos da câmara de vereadores disponibilizados na Biblioteca Batista Caetano em São João Del Rei, a lista de licenças comerciais, livros de viajantes do século XIX e inventários post-mortem sob a guarda do IPHAN - Instituto do Patrimônio Histórico e Artístico Nacional de São João Del Rei.

\section{Elites em perspectiva: a complexidade da sociedade colonial}

A formação da elite brasileira está imbricada na interação entre os grupos sociais e a coroa, que resultava na criação das hierarquias. Essa interação consubstanciava-se na distribuição de terras e cargos régios. A economia de dons e contra dons, tão utilizada pela nobreza da terra para a obtenção dos cargos régios passou a ser utilizada pela emergente elite mercantil para sua promoção social através do vínculo contratual estabelecido entre as famílias - em sentido mais amplo, que se refere às redes de parentesco e sociabilidade das elites - e a coroa. A inserção dos negociantes na economia do dom não representou a destituição dos privilégios da nobreza da terra, pois eles ocupavam os cargos mais diretamente ligados à sua ocupação, enquanto a última sobrevivia do exercício dos ofícios patrimoniais da burocracia (FRAGOSO, 2005; SAMPAIO, 2010; NIZZA, 2005; BICALHO, 2005).

A inserção dos negociantes no círculo de poder das elites se fazia pela prática da concessão de benesses da Coroa e pelas estratégias desenvolvidas no âmbito familiar. A ascensão social, para os que não nasciam nas melhores famílias, só era possível através do enriquecimento que possibilitava a conquista de terras e benesses governamentais e a inserção em redes familiares de potentados agrários, cuja hegemonia já estava consolidada (FRAGOSO, 2005; SAMPAIO, 2010). Segundo Flory e Smith, esses negociantes investem na aquisição de propriedades fundiárias, na consolidação de laços de amizade e matrimônio, na obtenção de 
patente militar, no acesso a cargos camarários e na inserção em irmandades como estratégias de enobrecimento (FLORY e SMITH, 1978).

Em tese, pessoas que possuíam o defeito mecânico não podiam participar da governança, mas na prática a coroa teve que relevar esse critério por muitas vezes, visto que as receitas geradas pela mercancia eram imprescindíveis aos seus cofres. Prova da importância que tinha os cabedais dos negociantes na manutenção do governo, foi a definição fornecida ao termo mercador. Apesar de ir de encontro às pretensões da nobreza, a coroa classificou como efetivamente portadores do defeito mecânico apenas os mercadores de loja aberta, livrando dessa qualificação os grandes negociantes (NIZZA, 2005, p. 144).

O caráter peculiar do modelo de sociedade português implantado no Brasil possibilitou a diferenciação na formação da nobreza, permitindo uma maior flexibilidade com relação a quem poderia ou não ser considerado elite, de acordo com Fragoso et al "os trópicos redesenharam a hierarquia estamental do Antigo Regime, conferindo-lhe novas nuances ou, no mínimo, tornandoa mais plástica" (FRAGOSO et al, 2007, p.24).

As pesquisas acerca da formação da elite mineira são recentes e apresentam muitas lacunas. As primeiras interpretações são fundamentadas em relatos das autoridades metropolitanas que alimentavam um profundo desprezo por esta elite sem "berço" e nos discursos ressentidos dos inconfidentes, fundadas, portanto, em preconceitos particulares. É a visão que prevalece nos estudos de Laura de Mello e Souza e Sérgio Buarque de Holanda (SOUZA, 2006; HOLANDA, 1985), que apresentam respectivamente, a imagem de uma sociedade conflituosa, instável com uma nobreza sem os valores tradicionais, composta por "aventureiros e arrivistas" e uma sociedade sem luzimento e civilidade, marcada por aluvionismo social e pela busca por distinção.

Prospecções mais recentes tendem a utilização de outras fontes que possibilitam alcançar resultados menos tendenciosos. As pesquisas de Carla Almeida apontam um caminho diverso para interpretar a origem dessa elite, sustentando que a consolidação das posições na hierarquia social vinha por meio do enobrecimento das gerações sucessivas de mineradores. Há indícios do amplo envolvimento nas atividades de mineração que compunha aliada ao grande comércio, ao tráfico negreiro, a usura e as atividades agrárias, o conjunto das ocupações dos homens bons de 
Minas (ALMEIDA, 2005-a, 2005-b, 2006; GRAÇA FILHO, 2007). As atividades para as quais essa elite confluía e a tentativa de inserção nas camadas mais nobres da sociedade demonstrava a procura por uma sedimentação das posições sociais desses homens. Do mesmo modo, é preciso considerar que as atividades agrícolas exigiam certo grau de enraizamento. Dessa forma, podemos interpretar a implantação da agricultura no território desde o início da exploração mineral (LENHARO, 1979; GUIMARÃES \& REIS, 1986; ZEMELLA, 1990; PRADO JUNIOR, 1961) como um obstáculo ao aluvionismo social e uma forma de estabilidade da população local.

A Comarca do Rio das Mortes foi um importante provedor de gêneros para o abastecimento dos distritos ligados às atividades de extração mineral ao longo do século XVIII (LIBBY e GRAÇA FILHO, 2003) e posteriormente, o desenvolvimento imponente da sua economia agrária, potencializado pela intensificação do comércio com a praça carioca, por ocasião da transferência da Corte Real para o Brasil, possibilitou a formação de grupos hegemônicos (GRAÇA FILHO, 2002; LENHARO, 1979). A vila, situada na região sul de Minas era um dos dois maiores entrepostos comerciais no século XIX. Sua situação geográfica privilegiada a beneficiava com diferentes canais de escoamento da produção ${ }^{4}$. Viajantes do século XIX, como Spix e Martius (1976) e Saint-Hilaire (2002) sugeriram que a praça comercial são-joanense era extremamente ativa e diversificada. O comércio envolvia atividades de exportação e provimento das demandas internas, sendo a quantidade expressiva de gêneros digna de nota.

O comércio em São João del-Rei assumiu um papel central na liquidez da economia regional rural, atuando como ponte entre Minas e a praça mercantil carioca, arbitrando no provimento de escravos e crédito aos pequenos produtores e na redistribuição de mercadorias agrícolas e manufaturadas, processos que impulsionaram o enriquecimento do alto comércio sãojoanense (GRAÇA FILHO, 2002; LENHARO, 1979; LIBBY, 1988; MARTINS, 1996). Mas, esse quadro sempre foi assim? Esse mercado regional sempre teve o mesmo prestígio desde quando as atividades mineradoras e agrícolas ocupavam um lugar de destaque na composição dos ativos das grandes fortunas locais?

\footnotetext{
${ }^{4}$ Como afirma Lenharo o "centro das exportações mineiras tinha sede em São João del Rey que, juntamente com Barbacena, constituíam os dois pólos atacadistas". Ainda segundo o autor: "São João Del Rey drenava a maior parte das exportações de subsistência mineira". (LENHARO. 1979:89).
} 
A observação atenta nos mostrou que nos primeiros anos parcela considerável dos homens considerados como elite não possuía vultosas fortunas, e os que as possuíam, apresentavam grande quantia delas comprometidas em dívidas passivas. Inferimos que a gênese dessa elite esteve atrelada à subordinação ao capital externo, cumprindo uma trajetória ascendente até chegar a uma verdadeira elite de negociantes a partir do século XIX, sobretudo da década de $1831^{5}$.

\section{O perfil geral da elite econômica}

As informações da lista de $1756^{6}$ apontam que a maioria dos são-joanenses abastados estava envolvida em atividades ligadas ao comércio. Ainda que também fossem expressivas as atividades agrárias e mineradoras como pode ser observado através do primeiro quadro, que nos fornece uma visão geral das principais ocupações dos homens bons da Comarca do Rio das Mortes.

\section{Quadro 1: Ocupação dos homens considerados ricos em 1756 para a CRM}

\begin{tabular}{|c|c|c|c|c|c|c|}
\hline \multirow{2}{*}{ Ocupação } & \multicolumn{2}{|c|}{ São José Del-Rei } & \multicolumn{2}{|c|}{ São João Del-Rei } & \multicolumn{2}{c|}{ CRM* } \\
\cline { 2 - 7 } & $\mathbf{N}^{\circ}$ absoluto & $\mathbf{\%}$ & $\mathbf{N}^{\circ}$ absoluto & $\boldsymbol{\%}$ & $\mathbf{N}^{\circ}$ absoluto & $\%$ \\
\hline Negociante & 16 & 24,5 & 17 & 37 & 33 & 30 \\
\hline Minerador & 19 & 29 & 9 & 19,6 & 28 & 25 \\
\hline Roceiro & 14 & 22 & 10 & 21,7 & 24 & 22 \\
\hline $\begin{array}{c}\text { S. } \\
\text { identificação }\end{array}$ & 16 & 24,5 & 10 & 21,7 & 26 & 23 \\
\hline Total & 65 & 100 & 46 & 100 & 111 & 100 \\
\hline
\end{tabular}

Fonte: Lista dos homens mais abastados da capitania feita pelo intendente da Comarca de Sabará Domingos Nunes Vieira

* CRM - Comarca do Rio das Mortes, representada na lista de abastados pelas Vilas de São João e São José

5 É importante ressaltar que a existência de menor número de inventários para o período intermediário pode influenciar nos resultados obtidos, assim como a heterogeneidade nas fontes e sua descontinuidade podem dificultar uma análise quantitativa e comparativa. Contudo, mesmo considerando as fragilidades das fontes, entendemos que a análise realizada oferece previsões consideráveis a respeito dessa elite cuja trajetória permanece ainda obscura.

Oficina do Historiador, Porto Alegre, EDIPUCRS, v. 7, n. 1, jan./jun. 2014, p. 4-22. 10 
A percepção do vultoso envolvimento dos homens mais ricos de São João del-Rei com as atividades mercantis convergiu para a utilização dos inventários dos indivíduos licenciados para o comércio em 1779 no intuito de reconstituir uma imagem da elite no período posterior à lista do intendente e anterior as pesquisas de Graça Filho (2002). Como a média de monte-mor mais alta registrada remetia aos inventários pertencentes a negociantes, consideramos que houve uma trajetória ascendente das fortunas construídas através das atividades comerciais, e que, por isso, os indivíduos atrelados à mercancia assumiram o papel de elite econômica em São João.

Embora a quantificação dos dados nos aponte para a predominância de uma elite voltada para o comércio, visto que é arrolado como carro chefe da maioria das fortunas, veremos como a desagregação de dados demonstra uma realidade muito mais complexa.

A fortuna de Manoel Antunes Nogueira, relacionado em 1756 na categoria negociante, estava intrinsecamente imbricada nas atividades agrárias e com o financiamento de pequenas unidades produtoras. Talvez esse consórcio entre atividades tenha proporcionado a manutenção da sua fortuna mesmo tendo decorrido o prazo de 24 anos desde o rol de abastados até a feitura do seu inventário. Os homens ligados estritamente à mercancia nesse momento, não apresentam montes consideráveis. É o caso de Antônio da Motta Teixeira ${ }^{7}$ que não possuía nenhum bem que indicasse seu envolvimento em outra atividade, até mesmo a lista de seus bens móveis era muito reduzida. Inventariado em 1790, 34 anos após a lista de 1756, seu pecúlio (218\$575) não alcançava sequer a cifra de um conto de réis. Sugerimos que o comércio local nesse momento não era suficiente para garantir, sozinho, a acumulação de riquezas. Conclusão que também parece plausível para os outros negociantes envolvidos na lista de licenças nesse mesmo período. Somente a partir de 1812 pode ser observado um avanço das fortunas são-joanenses, principalmente no intervalo entre 1831 e 1850. Essas informações podem ser interpretadas como um indício da fragilidade do comércio ainda no Setecentos.

Nossa investigação expôs um vínculo entre as elites são-joanenses e o desempenho dos poderes locais, seja na ocupação de cargos camarários ou de patentes militares. Identificamos, ao

\footnotetext{
${ }^{6}$ Lista feita por Domingos Nunes Vieira, intendente da Comarca de Sabará, que escreveu ao secretário de Estado em 24 de julho de 1756. Dos 42 nomes listados para São João Del-Rei, rastreamos inventários de 12 e dos 65 nomes arrolados. Em São José, conseguimos localizar 13 inventários.

${ }^{7}$ IPHAN- São João Del Rei. Inventário cx.272, ano 1790, São João Del Rei
}

Oficina do Historiador, Porto Alegre, EDIPUCRS, v. 7, n. 1, jan./jun. 2014, p. 4-22. 
mesmo tempo, uma relação entre seus membros e o Império Português. Ao contrário do que propõe Laura de Mello e Souza (SOUZA, 2006) que acreditava que a formação social de Minas era desenraizada, sem memória, pendular e avessa às normas, onde as convenções e códigos estamentais perdiam qualquer sentido, encontramos uma elite envolvida na governança local, preocupada com patentes e títulos. Preocupações que na interpretação de Fragoso et al “mostravam que eles não desejavam em nenhuma hipótese subverter a ordem social, mas sim ocupar as suas posições mais elevadas" (FRAGOSO, 2007, p.28). Nessa perspectiva, o segundo quadro demonstra a inserção político social desses homens.

\section{Quadro 2: Inserção político social da elite setecentista}

\begin{tabular}{|c|c|c|c|c|c|}
\hline \multicolumn{3}{|c|}{ Ocupação de postos nas ordenanças } & \multicolumn{3}{|c|}{ Inserção em ordens e irmandades religiosas } \\
\hline Posto & $\%$ & $\mathbf{N}^{\circ}$ absoluto & \multirow{3}{*}{ Ordens Terceiras } & $\%$ & $\mathbf{N}^{\circ}$ absoluto \\
\hline Nenhuma patente & 61,53 & 7 & & & \\
\hline Capitão & 13,3 & 2 & & 38,46 & 5 \\
\hline Tenente & 7,69 & 1 & \multirow{3}{*}{ Irmandades } & \multirow{3}{*}{15,38} & \multirow{3}{*}{2} \\
\hline Guarda-mor & 7,69 & 1 & & & \\
\hline Cavaleiro da Ordem de Cristo & 7,69 & 1 & & & \\
\hline Total & 97,9 & 12 & Total & 53,8 & 7 \\
\hline
\end{tabular}

Fonte: Inventários post-mortem da CRM disponibilizados pelo IPHAN de São João del-Rei

Ocupar cargos na governança também era uma maneira de ascender socialmente, segundo Sampaio "a ocupação de semelhantes postos também trazia grandes vantagens [...] os inseria na economia das mercês como importantes credores da atenção régia" (SAMPAIO, 2010, p. 470).

Alguns membros dessa elite ocuparam cargos camarários. E, como pudemos constatar através da análise dos montes-mor, nem todos eram dotados de grossos cabedais ou de qualquer outra menção de fidalguia no momento da realização do inventário. Tomemos como exemplos o capitão-mor João de Matos, Caetano da Silva, Antônio de Freitas e Manoel Antunes Nogueira.

O capitão-mor João de $\operatorname{Matos}^{8}$ teve seu monte-mor avaliado em 6:362\$322. Além de possuir o título de capitão, foi juiz ordinário da câmara de São João de $1748-1755^{9}$ e membro da ordem terceira de São Francisco. Como comprova o seu inventário, não era possuidor de imensa

\footnotetext{
${ }^{8}$ IPHAN - São João Del Rei. Inventário cx.153, ano 1758, São João Del Rei.
}

${ }^{9}$ Acórdãos e termos de vereança livro 3, 1748-1755. 
fortuna e era negociante de fazendas e usurário que segundo a definição de Faria (1998), seriam os negociantes envolvidos com o comércio de fazendas, objetos de pequeno porte e miudezas, praticando paralelamente o empréstimo a juros.

Quanto a Caetano da Silva, inventariado em $1774^{10}$, foi vereador em 1737. Apesar de esse documento estar muito danificado, comprovamos que seu monte-mor era equivalente a 1:437\$766. Podemos supor que em 18 anos - contagem feita a partir de 1756 - seu patrimônio pode ter sofrido considerável redução, ou então, que se tratava de um homônimo, visto que em 1763 figurava entre os envolvidos com o tráfico de escravos com um carregamento de 14 'peças'. Como salientava o governador Gomes Freire de Andrade, as fortunas aqui se construíam e sublimavam com a mesma intensidade (NIZZA, 2005).

Do mesmo modo como podemos supor uma instabilidade das fortunas no Setecentos e a ocupação dos cargos e patentes por pessoas de menor qualidade, temos que considerar as conjecturas de Almeida. A autora propõe que, a julgar pela extensão da lista feita por Domingos Vieira, este não foi muito criterioso para designar a elite, incluindo pessoas em dificuldades financeiras. Argumenta também que a lista e os inventários post-mortem refletem momentos diferentes da vida do sujeito numa escala descendente de prosperidade (ALMEIDA, 2005a).

Por sua vez, o capitão Manoel Antunes Nogueira e Antônio de Freitas, ambos vereadores em 1737 e 1750 respectivamente, possuíam grandes fortunas construídas através do comércio. Se enquadravam na descrição de negociante usurário ou financista fornecida por Faria (1998), categoria referente a negociantes que não possuíam mercadorias. Seu capital era fortalecido a partir do empréstimo a juros. O capitão Manoel Antunes Nogueira ${ }^{11}$ possuía monte equivalente a 67:253\$654, no entanto, suas dívidas passivas comprometiam em torno de 47\% do valor monte mor. Situação parecida a de Antônio de Freitas $^{12}$, cujo inventariante foi o próprio capitão Nogueira - tal fato remete à construção das redes clientelares entre a 'elite' local. Seu monte-mor avaliado em 60:030\$131, tinha aproximadamente $29 \%$ comprometido em dívidas passivas.

Nos dois últimos exemplos, as maiores fortunas de São João no século XVIII, percebemos que grande parcela dos montes-mor estava comprometida em dívidas. Dentre as maiores fortunas

\footnotetext{
${ }^{10}$ IPHAN- São João Del Rei. Inventário cx.c-02, ano 1774, São João Del Rei.

${ }^{11}$ IPHAN- São João Del Rei. Inventário cx.c-51, ano 1780, São João Del Rei.

${ }^{12}$ IPHAN- São João Del Rei.Inventário cx.94, ano 1763, São João Del Rei.
} 
de São João da segunda metade do século XVIII, 50\% tinham boa parcela delas comprometida em dívidas passivas ${ }^{13}$. Isso aponta para a dependência de capital, provavelmente, externo à região. Basta comparar os terceiro e quarto quadros.

\section{Quadro 3: Relação de dívidas das maiores fortunas de São João séc. XVIII}

\begin{tabular}{|c|c|c|c|c|}
\hline \multicolumn{7}{|c|}{ Século XVIII } \\
\hline Inventariado / Ocupação & Dividas (+) & Dividas (-) & $\%(-) *$ & Total de Monte mor \\
\hline Manoel Antunes Nogueira / negociante & 44672136 & 31931053 & 47 & 67253654 \\
\hline Antônio de Freitas/ negociante & 29538962 & 17704916 & 29 & 60030131 \\
\hline Manoel Ferreira Pereira/roceiro & 13194236 & - & 0 & 43252833 \\
\hline Manoel Rodrigues Gondim / minerador & 4210000 & $* *$ & - & 31220000 \\
\hline Francisco Ribeiro de Souza / mercador & 3746706 & 8589666 & 38 & 22286817 \\
\hline João Soares de Bulhões/roceiro & 3562466 & 608067 & 17 & 21739689 \\
\hline
\end{tabular}

Fonte: Inventários post-mortem da CRM disponibilizados pelo IPHAN de São João del-Rei

* porcentagem do monte comprometida em dívidas passivas

**consta dever a 17 credores, mas faltam as folhas de dívida passiva

Podemos aventar que as redes clientelares em que se envolviam tinham abrangência não apenas local e interprovincial, incluíam também Portugal. Podemos ilustrar essa afirmação através dos casos do guarda-mor Manoel Rodrigues Gondim, do capitão Manoel Antunes Nogueira e também do sargento mor Manoel Rodrigues Pereira da vila vizinha, São José.

No inventário do guarda-mor Manoel Rodrigues Gondim consta um oitavo no contrato do dízimo do tesouro e cento e vinte oito avos no contrato de entradas e da dízima do Rio de Janeiro e Passagem do Paraibuna, que se achava em mãos de seu tio José Alves Gondim, em Portugal. Já o capitão-mor Manoel Antunes Nogueira, português, arrematou o contrato das passagens do Porto Real e Rio Grande, pela quantia de trinta contos quinhentos e doze mil e noventa e nove reis pelo período de nove anos ${ }^{14}$. De acordo com Sampaio, a arrematação de contratos estava atrelada à "boa capacidade financeira" e de uma "rede bem articulada de procuradores que representassem os interesses do arrematante" (SAMPAIO, 2010, p. 468) uma vez que as arrematações aconteciam em Lisboa.

${ }^{13}$ É importante ressaltar que o inventário de Manoel Rodrigues Gondim está extremante fragmentado não sendo possível identificar qual o valor das suas dívidas passivas. Considerando que ele tinha 17 credores, podemos supor que seu caso não fosse diferente.

${ }^{14}$ IPHAN- São João Del Rei. Inventário cx.c-13, ano 1763, São João Del Rei. IPHAN- Inventário cx.c-03, ano 1763, São João Del Rei.

Oficina do Historiador, Porto Alegre, EDIPUCRS, v. 7, n. 1, jan./jun. 2014, p. 4-22. 


\section{Quadro 4: Relação de dívidas das maiores fortunas de São João séc. XIX}

\begin{tabular}{|c|c|c|c|c|}
\hline \multicolumn{5}{|c|}{ Século XIX } \\
\hline Inventariado / Ocupação & Dividas (+) & Dividas (-) & $\%(-)^{*}$ & Total de Monte mor \\
\hline Francisco José Dias negociante & 249793084 & - & 0 & 301413326 \\
\hline Francisco P. de Almeida Magalhães negociante & 67313680 & 62697567 & 55 & 113689863 \\
\hline Manoel J. da Costa Machado negociante & 55820335 & 3987865 & 6 & 70502035 \\
\hline Antônio José Pacheco negociante & 43845123 & 2362269 & 4 & 59613760 \\
\hline
\end{tabular}

Fonte: Inventários post-mortem de São João del-Rei e em A princesa do Oeste

* porcentagem do monte comprometida em dívidas passivas

O sargento mor Manoel Rodrigues Pereira também se mostra bem articulado, se pudermos considerar as procurações como demonstração de suas relações inter-provinciais e com a metrópole. O documento está extremamente fragmentado, mas foi possível constatar que as pessoas escolhidas para representar a família do inventariado eram de alguma distinção, figurando entre eles doutores, indivíduos com patentes no exército e mesmo o próprio capitão Manoel Antunes Nogueira. Essa procuração permite interpretar que os negócios do falecido tinham abrangência intra e interprovincial e mesmo, com a metrópole sendo nomeados procuradores para representar os interesses da família nas Comarcas do Serro do Frio, Vila Rica, Goiás, Cuiabá, São Paulo e Santos; nas cidades do Rio de Janeiro, Lisboa e Évora ${ }^{15}$.

Os homens de origem portuguesa mostraram através dos seus testamentos anexados ao inventário, guardar estreitas relações com o reino, uma vez que a relação de herdeiros aponta a maior parte (sobrinhos e irmãos), como residentes em Portugal.

Ser nobre durante o período colonial implicava muito mais do que ocupar cargos na governança ou pertencer a alguma ordem religiosa. Envolvia também viver como nobre. A ostentação, a diferenciação social através de uma vida faustosa era, nas outras capitanias, uma forma de enobrecimento ainda que pudesse trazer a ruína de algumas fortunas ${ }^{16}$.

À exceção de uns poucos, os homens arrolados como elite em São João, parecem ter tido uma vida rústica ${ }^{17}$ e estar em processo de construção de suas fortunas. Creio que eles eram a elite

\footnotetext{
15 IPHAN- São João Del Rei. Inventário cx.c-22, ano 1733, São José Del Rei.

${ }^{16}$ Cf. NIZZA, 2005:137. Antonil e Pedro Taques apontam a ostentação como causa da ruína de muitas fortunas.

17 A comprovação da vida rústica que levavam pode ser feita a partir da observação da composição dos bens (mobiliário, utensílios...) demasiadamente simples. A ausência de menção ao vestuário (descrito apenas enquanto mercadoria) pode nos levar a crer na sua simplicidade, uma vez que qualquer bem que pudesse ser transformado em
}

Oficina do Historiador, Porto Alegre, EDIPUCRS, v. 7, n. 1, jan./jun. 2014, p. 4-22. 15 
porque suas qualidades se sobressaiam em relação ao resto da população, talvez por ser bem relacionada, uma elite em 'potencial'. Somente a partir da segunda década do Oitocentos os grupos proeminentes se firmariam como elite econômica, entendendo como tal, grupos com maiores fortunas. A maior parcela dos homens arrolados como elite era envolvida com a mercancia. Seria prudente lembrar que isso os incluía na parcela da população marcada pelo trabalho mecânico.

\section{Quadro 5: Perfil dos principais investimentos dos inventariados}

\begin{tabular}{|c|c|c|c|c|}
\hline \multirow{2}{*}{$\begin{array}{c}\text { Principais } \\
\text { Investimentos }\end{array}$} & \multicolumn{2}{|c|}{ Século XVIII } & \multicolumn{2}{c|}{ Século XIX } \\
\cline { 2 - 5 } & $\mathbf{N}^{\circ}$ inventários & $\mathbf{\%}$ & $\mathbf{N}^{\circ}$ inventários & $\%$ \\
\hline Escravos & 4 & 33,4 & - & - \\
\hline Imóveis & 1 & 8,3 & 1 & 20 \\
\hline Dívidas Ativas & 6 & 50 & 4 & 80 \\
\hline Escravos ao Ganho & 1 & 8,3 & - & - \\
\hline Total & $12 *$ & 100 & 5 & 100 \\
\hline
\end{tabular}

Fonte: Inventários post-mortem da CRM disponibilizados pelo IPHAN de São João del-Rei e em A princesa do Oeste... * No caso de Manoel Rodrigues Gondim, como no inventário consta apenas um total da maior parte dos bens, não foi possível identificar qual a maior parcela de sua fortuna. Por isso o documento não aparece contabilizado.

O quinto quadro apresenta um perfil para os principais investimentos dos inventariados. Para o Setecentos, percebemos que a parcela majoritária (50\%) dos montes analisados era aplicada em dívidas ativas. A prática de usura era atrelada a investimentos em áreas diversas. As conclusões convergem com as de Almeida que apresenta as dívidas ativas como "o ativo de maior destaque no conjunto das fortunas" o que pode ser considerado um indício de "que esses grupos eram os detentores do crédito na sociedade mineira” (ALMEIDA, 2005-a, p. 367). Só não podemos desconsiderar que as pesadas dívidas passivas dos principais fornecedores de crédito em Minas no Setecentos também sugerem uma situação de dependência, provavelmente externa a região.

O crédito estava concentrado nas mãos dos negociantes, $77,1 \%$ das dívidas ativas detectadas nos inventários analisados correspondia à atuação de 5 homens. É importante considerar, no entanto, que apenas 2 roceiros controlavam 15,6\% do crédito. A partir disso

renda era pautado. Nota-se a presença, em alguns casos, de utensílios mais caros como castiçais de prata, faqueiro de prata e outros. Segundo a interpretação de Sheila Faria em 'A Colônia em Movimento' peças caras ou mais

Oficina do Historiador, Porto Alegre, EDIPUCRS, v. 7, n. 1, jan./jun. 2014, p. 4-22. 16 
concluímos que no século XVIII o capital agrário também podia ser responsável pela liquidez do crédito em São João del-Rei, sendo parte ativa na prática usurária.

\section{Quadro 6: Distribuição do crédito por área de atuação dos são-joanenses abastados}

\begin{tabular}{|c|c|c|c|c|}
\hline Área de Atuação & Total & Média & \% & $\mathbf{N}^{\circ}$ de processos \\
\hline Roceiros & 16756702 & 8378351 & 15,6 & 3 \\
\hline Mineradores & 7850465 & 2616821 & 7,3 & 2 \\
\hline Negociantes & 82624501 & 16524900 & 77,1 & 7 \\
\hline Total & $\begin{array}{c}10723166 \\
8\end{array}$ & 35743889 & 100 & 13 \\
\hline
\end{tabular}

Fonte: Inventários post-mortem da CRM disponibilizados pelo IPHAN de São João del-Rei

Segundo a lista de 1756, os homens abastados estavam majoritariamente envolvidos com a prática mercantil. Ainda que esta assertiva corresponda à realidade, é possível perceber que tais atividades eram consorciadas com as agrícolas. O consórcio entre essas atividades pode ter sido responsável pela manutenção do patrimônio da elite setecentista. A posse de terras e demais meios de produção era mais do que um meio de nobilitação, era o que permitia conservar o patrimônio. Através da análise do inventário de Manoel Antunes Nogueira pudemos perceber que além de negociante, ele também era produtor rural. Possuía plantação de cana-de-açúcar (em sociedade com o coronel Francisco de Mendonça e Sá) e além dos animais de transporte necessários a sua profissão, possuía um grande rebanho.

Quanto a Manoel Ferreira Pereira, caracterizado como roceiro, podemos sugerir que além de produtor e pecuarista atuava como comerciante da própria produção. A enorme quantidade de animais de transporte pode ser indicativa da independência dessa unidade. Possuía o próprio engenho para beneficiamento da produção e os meios para transportá-la e negociá-la diretamente. Ele conseguiu uma licença comercial em $1780^{18}$.

Considerando todas as observações realizadas, argumentamos que a gênese da elite sãojoanense corresponderia a um momento em que a inexistência de um grupo mais qualificado, ou mais rico levou a Coroa a aceitar para seu serviço indivíduos sem muito prestígio. Aceitar que a riqueza, ao invés da nobreza, marcaria essa elite em seus primórdios, considerando a pequena

sofisticadas poderiam servir como objeto de penhora em um momento de dificuldades, ou seja, cabe a interpretação que ter tais objetos seria uma reserva, uma garantia e não ostentação.

Oficina do Historiador, Porto Alegre, EDIPUCRS, v. 7, n. 1, jan./jun. 2014, p. 4-22. 
relevância dos montes-mor da maioria dos indivíduos assim designados, implica na aceitação de que as suas fortunas, no século XVIII, eram instáveis. Podendo ampliar-se ou dilapidar-se em curtos espaços de tempo.

Inferimos ainda, que ao longo da segunda metade do Setecentos, a praça comercial sãojoanense não apresentava o mesmo vigor observado pelos viajantes e pelas análises de alguns autores realizadas para o século XIX. A mercancia e a usura, embora elementares na composição das maiores fortunas para o período, não pareciam suficientemente capazes de garantir autonomia, visto que os sujeitos que controlavam a liquidez estavam subordinados a outra fonte creditícia. Status que se alterou a partir do século XIX, quando a economia se tornou mais mercantilizada e ofereceu condições de independência frente ao mercado carioca. Desse modo, a partir da crise da mineração, a sedimentação do comércio enquanto sustentáculo da economia mineira gerou uma autonomia ascendente que fortaleceu os capitais ali sediados, sobretudo no decorrer do segundo quartel do Oitocentos.

\section{À guisa de conclusão}

Em linhas gerais, reconhecemos uma preocupação com o enobrecimento por meio da arrematação de contratos, da busca por patentes militares e da inserção em ordens e irmandades. No campo das representações sociais, percebemos que a ostentação que marcava a nobreza em outras capitanias não parecia ser um elemento característico dessa elite em seus primórdios. A vida rústica constatada a partir da observação dos bens inventariados contrastava com o "viver às leis da nobreza' nas outras regiões do Brasil colonial. Também é marcante o envolvimento desses indivíduos com o trabalho, símbolo da mácula mecânica. No campo financeiro, entendemos que as fortunas locais setecentistas eram instáveis e que mesmo os grandes financistas do período estavam subordinados a outra fonte creditícia. Tais conclusões indicam que em São João del-Rei galgar os mais altos postos na hierarquia social estivesse dissociado de 'ser nobre', ou então, que

${ }^{18}$ IPHAN- São João Del Rei. Inventário cx.c-22, ano 1764, São João Del Rei.

Oficina do Historiador, Porto Alegre, EDIPUCRS, v. 7, n. 1, jan./jun. 2014, p. 4-22. 
o rol de são-joanenses abastados refletiria a falta de rigor nos critérios que determinavam o que era ser elite nas Minas seticentista.

Sem a pretensão de ter conseguido esgotar as questões que envolvem a gênese da elite mineira, concluo esta análise ressaltando que essa elite local, até início do século XIX não parecia muito nobre, tampouco muito abastada. Na verdade, diferia bastante dos padrões da elite mercantil estudada por Graça Filho a partir de 1831, que dispunha de grossos cabedais, e também se dissociava da imagem de nobreza de sangue ou livre da mácula mecânica, requisito mais respeitado em outras capitanias. Além disso, o endividamento das maiores fortunas pode sugerir certa dependência da praça comercial são-joanense no século XVIII e sua concomitante fragilidade. Invertendo essa situação a partir do século XIX, quando a forte mercantilização consolida as grandes fortunas locais.

\section{REFERÊNCIAS BIBLIOGRÁFICAS}

ALMEIDA, Carla Maria Carvalho de. Homens ricos em Minas colonial In: BICALHO, Maria Fernanda; FERLINI, Vera Lúcia Amaral. Modos de governar: idéias e práticas políticas no Império português, séculos XVI-XIX. São Paulo: Alameda, 2005 a.

ALMEIDA, Carla Maria Carvalho de. De Vila Rica ao Rio das Mortes: uma mudança do eixo econômico em Minas colonial. Locus: Revista de história, Juiz de Fora, v.11, n.1 e 2, p. 137-160, 2005 b.

. Do Reino às Minas: o "cosmopolitismo" da elite mineira setecentista. In: FRAGOSO, João et alii (orgs.) Nas rotas do Império. Vitória: Edufes; Lisboa: IICT, 2006.

BICALHO, Maria Fernanda Baptista. "Elites coloniais: a nobreza da terra e o governo das conquistas. História e historiografia." in: MONTEIRO, Nuno G.F.; CARDIM, Pedro, CUNHA, Mafalda Soares (orgs.). Optma Pars:elites ibero-americanas do Antigo Regime. Lisboa: ICS, 2005.

BOBBIO, Norberto. Teoria das elites. In: BOBBIO, Norberto; MATTEUCCI, Nicola; PASQUINO, Gianfranco. (orgs). Dicionário de política. Brasília: EDUNB, 1992.

Oficina do Historiador, Porto Alegre, EDIPUCRS, v. 7, n. 1, jan./jun. 2014, p. 4-22. 
CHARLE, Christophe. Como anda a história social das elites e da burguesia? Tentativa de balanço crítico da historiografia contemporânea. In: HEINZ, Flávio M.(org.). Por outra história das elites. Rio de Janeiro: FGV, 2006.

CHARTIER, Roger. A história entre a geografia e a sociologia. In: CHARTIER, Roger. À beira da falésia: a história entre certezas e inquietude. Porto Alegre: Editora UFRGS, 2002.

O mundo como representação. In: CHARTIER, Roger. À beira da falésia: a história entre certezas e inquietude. Porto Alegre: Editora UFRGS, 2002.

FARIA, Sheila de Castro. A colônia em movimento: fortuna e família no cotidiano colonial. Rio de Janeiro: Nova Fronteira, 1998. (Coleção Histórias do Brasil). $2^{a}$ Reimpressão.

FLORY, Rae; SMITH, David Grant. Bahian merchants and planters in the seventeenth and early eigthteenth century. Hispanic American Historical Review, vol.58, no.4,1978. P.571-594.

FRAGOSO, João L. Homens de grossa aventura: acumulação e hierarquia na praça mercantil do Rio de Janeiro, 1790-1830. Rio de Janeiro: Civilização Brasileira, 1998.

- A nobreza vive em bandos: a economia política das melhores famílias da terra do Rio de Janeiro, século XVII, algumas notas de pesquisa. In: Revista Tempo, Niterói, v. 15, 2003.

- Elites econômicas em finais do século XVIII: mercado e política no centro-sul da América lusa. Notas de uma pesquisa. In: JANCSÓ, István (org.). Independência: história e historiografia. São Paulo: Fapesp/Hucitec, 2005.

FRAGOSO, João; ALMEIDA, Carla; SAMPAIO, Antônio Carlos Jucá. Conquistadores e Negociantes- Histórias de elites no Antigo Regime nos trópicos. América lusa, séculos XVI a XVIII.

FURTADO, Junia Ferreira. Novas tendências da historiografia sob Minas Gerais no período colonial. História da Historiografia. N², março 2009. pp.116 a 162.

GOUBERT, Pierre. História local. in: Revista História \& Perspectivas. Uberlândia, 45/57, jan/jun, 1992.

GRAÇA FILHO, Afonso de Alencastro. A princesa do Oeste e o mito da decadência de Minas Gerais: São João del Rei (1831-1888). São Paulo: Annablume, 2002.

GRAÇA FILHO, Afonso de Alencastro. "Fragmentos de memórias: impressões sobre São João del Rei” in VENÂNCIO, Renato Pinto; ARAÚJO, Maria Marta (orgs.). São João del-Rey, uma cidade no Império. Belo Horizonte: Secretaria de Estado de Cultura de Minas Gerais/Arquivo Público Mineiro, 2007, p. 47-66. 
HESPANHA, Antônio Manuel. Governo, elites e competência social: sugestões para um entendimento renovado da história das elites. In: BICALHO, Maria Fernanda; FERLINI, Vera Lúcia Amaral (orgs). Modos de governar: ideias e práticas políticas no império português, séculos XVI-XIX. São Paulo, Alameda, 2005, p.39-44.

HOLANDA, Sérgio Buarque de. Metais e pedras preciosas. In HOLANDA, Sérgio Buarque de (dir.). História Geral da Civilização Brasileira, 5ª ed., São Paulo, Difel, tomo I, v. 2, 1982.

LENHARO. Alcir. As tropas da moderação: o abastecimento da Corte na formação política do Brasil, 1808-1842. São Paulo: Símbolo, 1979.

LEVI, Giovanni. Sobre a micro-história. In: BURKE, Peter (org.). A escrita da História: novas perspectivas. São Paulo: Editora da Unesp, 1992.

LIBBY, Douglas Cole; GRAÇA FILHO, Afonso de Alencastro. Reconstruindo a liberdade Alforrias e forros na freguesia de São José do Rio das Mortes, 1750-1850. Varia Historia Julho 2003. no 30. pp.112-151

LIBBY, Douglas Cole. Transformação e trabalho em uma economia escravista. Minas Gerais no século XIX. São Paulo. Editora Brasiliense, 1988.

LIMA, Henrique Espada. A micro-história italiana: escalas, indícios e singularidades. Rio de Janeiro: Civilização Brasileira, 2006.

LINHARES, Maria Yedda. História Agrária. In: CARDOSO, Ciro Flamarion; VAINFAS, Ronaldo (Orgs.). Domínios da historia: ensaios de teoria e metodologia. Rio de Janeiro: Campus, 1997.

MARTINS, Roberto Borges. Minas e o trafico de escravos no século XIX, outra vez. In: SZMRECSÁNYI, Tamás \& LAPA, José Roberto do Amaral (orgs.). Historia econômica da Independência e do Império. São Paulo, HUCITEC/FAPESP/ABPHE, 1996. pp.99-130.

MATTOSO, José. História regional e local. In: A escrita da história. Lisboa: Editora Estampa. 1997, p. 169-180.

MATTOSO, Kátia M. de Queirós. Bahia, século XIX. Uma província no Império. Rio de Janeiro: Ed. Nova Fronteira, 1992.

MAXWELL, Kenneth. A devassa da devassa. São Paulo: Paz e Terra, 1973.

NIZZA, Maria Beatriz da Silva. Ser nobre na colônia. São Paulo:Ed. Da UNESP, 2005. 
SAMPAIO, Antônio Carlos Jucá de. Os homens de negócio e a coroa na construção das hierarquias sociais: o Rio de Janeiro na primeira metade do século XVIII. In: FRAGOSO, João; GOUVEIA, Maria ded Fátima (orgs.). Na trama das redes: políticas no império português, séculos XVI a XVIII. Rio de Janeiro. Civilização Brasileira. 2010, p. 459-484

SOUZA, Laura de Mello e. O sol e a sombra: política e administração na América portuguesa do século XVIII. São Paulo: Cia. das Letras, 2006.

\section{FONTES DOCUMENTAIS}

AHU- Rol dos homens mais abastados de Minas, feita por Domingos Nunes Vieira

Biblioteca Baptista Caetano - Acórdãos da câmara de vereadores.

IPHAN-SJDR - Fundo de Inventários post-mortem.

SAINT-HILAIRE, Auguste de. Segunda viagem a São Paulo e quadro histórico da Província de São Paulo. Brasília: Senado Federal, Conselho Editorial, 2002. Coleção O Brasil Visto por Estrangeiros.

SPIX, Johnn Baptist; MARTIUS. "Viagem de São João de Ipanema a Vila Rica". in: SPIX, Johnn Baptist; MARTIUS. Viagem pelo Brasil: 1817-1820. 3.ed. São Paulo: Melhoramentos, 1976. v.3.

ARTIGO ENVIADO PARA PUBLICAÇÃO EM: 08.03.2013 ACEITO PARA PUBLICAÇÃO EM: 08.06.2013 